\title{
The portable proton exchange membrane fuel cell's forced convection and cooling
}

\author{
Shimei Sun ${ }^{1, a^{*}}$, Xinyu Zhang ${ }^{2, b}$ andLei Feng ${ }^{3, c}$ \\ 1Jilin Jianzhu University, Changchun,China \\ 2 Jilin Jianzhu University, Changchun, China \\ 3 Jilin Normal University, Changchun,China \\ asunshir@163.com, ${ }^{\mathrm{b}}$ 278338162@qq.com, ${ }^{\mathrm{c}}$ 1009562702@qq.com \\ * please mark the corresponding author with an asterisk
}

Keywords: Proton exchange membrane fuel cell; Temperature change; Numerical simulation, Forced convection and cooling

Abstract..The low- power and portable proton exchange membrane fuel cell has the features of quick start, high power density and efficient energy conversion. It is widely used in the small equipment's power source devices. However, the characteristics of temperature change of proton exchange membrane fuel cell is one of the heat management research. This thesis studies the influential factors of proton exchange membrane fuel cell when it compulsively convections and cools. Through the way of numerical simulation to build 3D mathematical model, using audio-visual and thermal energy coupling, it gains the key parameters' distributional characteristics which influence the cell's compulsive convection and cooling.

\section{Introduction}

The fuel cell has a high efficiency, which has no pollution to the environment, which makes it have great application prospect in the portable power supply. Compared to the portable power supply, the traditional fuel cell system is very complex. In order to simplify the traditional fuel cell system, the air cooling power reactor is a feasible method. Air-cooled fuel cell electric reactor simplifies the cooling system, air compressor or air pump, the humidifying system in the stack and so on. This makes fuel cell more convenient in portable power applications. As a result, it is necessary to study portable air-cooled electric reactor.

When the fuel cell is working, it will also produce a certain quantity of heat. If proton exchange membrane fuel cell's all the heat of reaction can convert into electrical energy, the stack's output voltage is $1.48 \mathrm{~V}$ when water discharges in the form of liquid or $1.25 \mathrm{~V}$ in the form of gas. There is a big difference between the actual battery voltage and these two values. The reason is that there is no conversion of partial energy into electrical energy, but in the form of heat.

\section{Working principle of proton exchange membrane fuel cell}

(1) the hydrogen molecule is decomposed into protons and released electrons by the catalytic effect of the catalyst on the catalytic layer after GDL. Anode:

$$
2 \mathrm{H}_{2} \rightarrow 4 \mathrm{H}^{+}+4 e^{-}
$$

(2)Proton through the membrane goes to the cathode catalytic layer, the electron goes from the outer circuit to the cathode due to the electron passing, the electronic circuit form the current to run the external work.

(3)At the cathode, the oxygen reaches to yhr cathode catalysis layer by the cathode diffusion layer. Under the action of the cathode catalyst, the reaction of oxygen with the proton through the membrane and the electrons in the outer circuit generates the water. Cathode:

$$
\mathrm{O}_{2}+4 e^{-}+4 \mathrm{H}^{+} \rightarrow 2 \mathrm{H}_{2} \mathrm{O}
$$


(4)Total response:

$$
2 \mathrm{H}_{2}+\mathrm{O}_{2} \rightarrow 2 \mathrm{H}_{2} \mathrm{O}
$$

\section{Air Forced Convection And Cooling}

Air cooling is a kind of technology that takes away the heat in the air by the air flowing. Compared to other ways, the air cooling structure is relatively simple, safe and convenient. Air cooling method can be divided into forced convection cooling and natural convection cooling. Forced convection cooling refers to work to air by fan. The flowing wind takes away a lot of heat to the cooling effect. When battery pack's heat is small, Natural air cooling technology can be used, the battery turns to the battery box through heat conduction, convection and radiation to, Then battery box displaces heat through the air convection or heat radiation to exchange the surrounding thermal. When the heat is large, the forced air cooling technology is used. Reasonable duct design, choose reasonable fan。 this way is conducive to improve the cooling effect, this paper talks about forced air convection cooling. As shown is the illustration of the natural convection of air.

Fuel cell work in natural convection, the flow characteristics of the air flow, the internal heat and mass transfer characteristics of the battery, and the electrochemical characteristics of a very strong coupling. The use of numerical calculation method is helpful to reveal the internal phenomenon of the battery, so as to improve the performance of the battery, and keep the battery in the stable working range of normal work.

In order to improve the air natural convection type proton exchange membrane fuel cell performance and to understand internal coupling phenomenon, a three-dimensional mathematical model is established. Based on the finite volume method and the finite difference method, the model are solved. The distribution characteristics of the key parameters is gained which affecting the performance of the cells.

\section{Mathematical model}

\section{The mathematical model description of the electrode}

(1)The catalyst layer is described by the crowding index model. The concentration of hydrogen and oxygen dissolved in the surface of crowding index is described by the Henry's law; (2) The charge transport current density is described by Using Butler-Volmer electrodynamics expression. The catalyst layer can be regarded as the boundary of the charge transfer; (3) The diffusion layer and the catalyst layer both can be regarded as porous media model. The flow of gas in porous media can be described by the Darcy's law. The mechanical parameters of the gas flow rate, pressure and others can be obtained in the diffusion layer and catalyst layer by the Darcy's law; (4) The diffusion and convection of the cathode and the anode are apiece described by a multi-component diffusion equation of Mexwell -Stefan.

\section{The mathematical model of fluid channel}

The conservation equation based on the analysis of the flow field mainly consists of the mass conservation equation, the momentum conservation equation, the component conservation equation and the energy conservation equation.

(1)The mass conservation equation is the continuity equation, supporting the gas is a continuous medium and in the condition of low speed flow. The equation is:

$\nabla g \rho \mu)=S_{m}$ 
Where, $\rho 、 \mu 、 S_{m}$ respectively represents the gas density, gas velocity and gas mass source term. For $S_{m}$, there are different expressions for different computational regions.

(2)The law of the momentum conservation equation is:

$$
\frac{1}{\varepsilon}\left[\frac{\partial \rho \mu}{\partial t}+\frac{1}{\varepsilon} \nabla g(\rho \mu r)\right]=-\nabla p+\nabla g+S_{u}
$$

Where: $p 、 \dot{\mu} 、 \varepsilon 、 S_{u}$ respectively represents the gas pressure, the viscosity coefficient, porosity and velocity source of gas.

(3)The law of the component conservation equations is:

$$
\frac{\partial}{\partial t}\left(\varepsilon^{e f f} C_{i}\right)+\nabla q\left(-D_{i}^{e f f} \nabla C_{v}\right)+\nabla q\left(\mu_{g} C_{i}\right)=S_{i}
$$

Where: $C_{i} 、 C 、 D_{i}^{\text {eff }} 、 \varepsilon^{\text {eff }} 、 S_{i}$ respectively represents the component concentration, concentration, component effective diffusion coefficient, porosity and component diffusion source. "I" and "V" are component codes which respectively represents Oxygen, nitrogen and water in the cathode, while nitrogen and water in the anode. The first term on the left is unsteady. The second is the diffusion terms. The third is the convective source.

In the channel and the diffusion layer, the component source term is 0 . In the catalyst layer, the components source terms are respectively hydrogen, oxygen and water.

$$
S_{\mathrm{H}_{2}}=-\frac{1}{2 F} i_{a} \quad S_{\mathrm{O}_{2}}=-\frac{1}{4 F} i_{c} ; \quad S_{\mathrm{H}_{2} \mathrm{O}}=\frac{1}{2 F} i_{c}
$$

Where: $i_{a}, i_{c}$ are the volume current density of the anode and the cathode.

(4)The net migration rate equation in the proton exchange membrane:

$$
\left.\varepsilon_{m} \frac{\partial c_{w}}{\partial t}+\nabla \oint \frac{n_{d} \mathrm{I}}{F}-D_{w} \nabla c_{w}\right)=0
$$

Where: $n_{d}$ is the transfer number of reacting charge; $F$ is the Faraday constant $\left(98487 \mathrm{Cgnol}^{-2}\right)$

(5)The energy conservation equation is:

$$
\left.\frac{\partial\left(\varepsilon \rho c_{p} T\right)}{\partial t}+\nabla\left(\varepsilon \rho c_{p} \stackrel{r}{\mu} T\right)=\nabla \mathbf{g} k^{e f f} \nabla T\right)+S_{Q}
$$

Where: $c_{p} 、 k^{\text {eff }} 、 T 、 S_{Q}$ respectively represents the specific heat at constant pressure, effective thermal conductivity, temperature and energy source; The first term on the left is the unsteady one and the second is the convection term. The first term on the right is a diffusion term and the second is energy source.

(6)The thermal convection energy equation is:

$$
S_{\text {out }}=\left(m_{H_{2}} C_{H_{2}}+m_{\text {air }} C_{\text {air }}\right)\left(T_{a}-T_{W}\right)
$$

Where: $S_{\text {out }} 、 C_{H_{2}} 、 C_{\text {air }} 、 m_{H_{2}} 、 m_{\text {air }} 、 T_{a} 、 T_{W}$ respectively represents the heat consumption by natural convection heat, Specific heat of hydrogen and oxygen, the quality of the hydrogen and oxygen, the temperature of the battery, the environment temperature.

(7)The thermal radiation energy equation is:

$$
S_{r a d}=\varphi \mathrm{gA}_{s} \Phi\left(T_{a}-T_{W}\right)^{4}
$$

Where: $\varphi 、 \mathrm{~A}_{s} 、 \sigma$, respectively represents exterior blackness coefficient $(0.8$ and 0.3 in simulations), the area of the battery, Stefan Boltzmann constant. 


\section{The results and analysis of the numerical simulation}

This thesis studies the effective on battery temperature by air forced convection cooling in the proton exchange membrane fuel cell thermal management. According to the battery's heat and mass transfer phenomena combined with chemical reaction characteristics, a three dimensional numerical simulation model is built to analyze the different boundary conditions. It takes multiple sets of parameters to simulate and uses different results to analyze the reasons.

\section{The influence of convection velocity cooling mode}

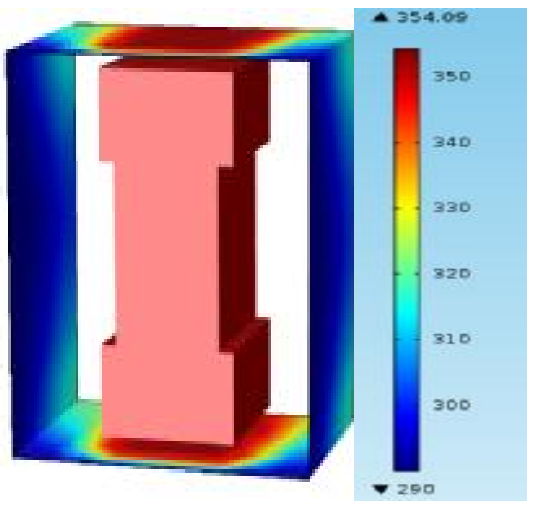

Figure 1. When the cooling temperature is $290 \mathrm{k}$, speed is $50 \mathrm{~cm} / \mathrm{s}$ and battery temperature $290 \mathrm{~K}-354.09 \mathrm{~K}$.

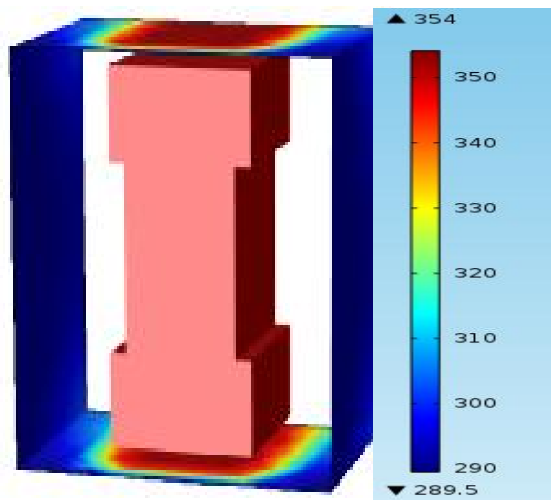

Figure 2. When the cooling temperature is $290 \mathrm{k}$, speed is $120 \mathrm{~cm} / \mathrm{s}$ and battery temperature is $289.5 \mathrm{~K}-354 . \mathrm{K}$.
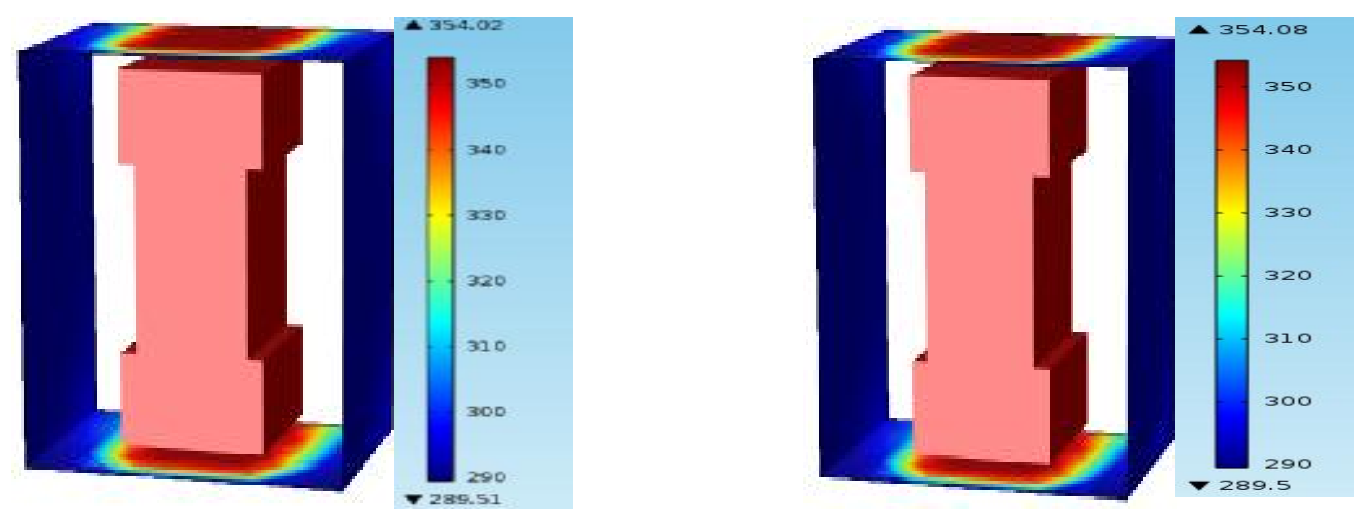

Figure 3. When the cooling temperature is $290 \mathrm{k}$, speed is $80 \mathrm{~cm} / \mathrm{s}$ and battery temperature is $289.51 \mathrm{~K}-354.02 \mathrm{~K}$.
Figure 4. When the cooling temperature is $290 \mathrm{k}$, speed is $200 \mathrm{~cm} / \mathrm{s}$ and the battery temperature is $289.5 \mathrm{~K}-354.08 \mathrm{~K}$.

The reason is that the increase of wind speed can increase the mass transfer in the battery, and effectively reduce the temperature of the stack, and take away the water in the stack so that the water content in the film is reduced. When the temperature of the battery is in a certain value, the increase of the wind speed can decrease the temperature of the battery. Then the battery performance is increased. But the size of the wind speed can also affect the battery temperature. when the wind is too large, the battery cooling temperature will increase rapidly. At different loads, the wind speed which battery needs is different when it stably works. 


\section{The influence of convection temperature on cooling mode}
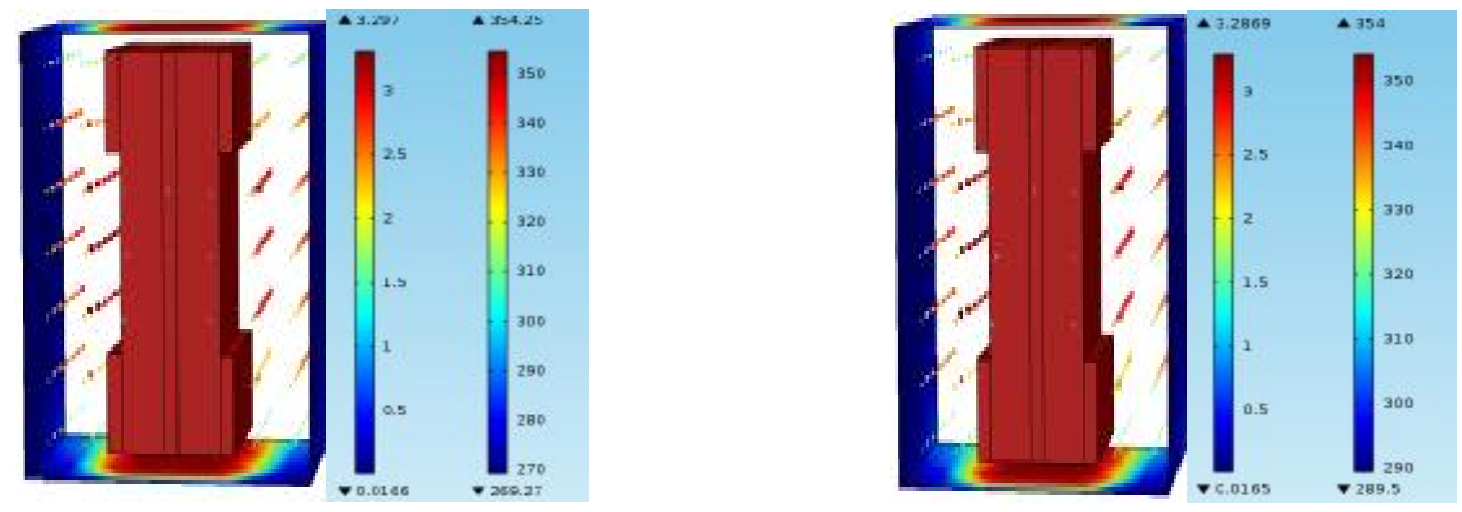

\begin{tabular}{|l|l|}
\hline $\begin{array}{l}\text { Figure 5. Wind speed of } 120 \mathrm{~cm} / \mathrm{s} \text {, cooling } \\
\text { temperature is } 270 \mathrm{k} \text { and battery temperature } \\
269.27 \mathrm{~K}-354.25 \mathrm{~K} .\end{array}$ & $\begin{array}{l}\text { Figure } 6 . \text { wind speed of } 120 \mathrm{~cm} / \mathrm{s} \text { and cooling } \\
\text { temperature is } 290 \text {, the battery temperature } \\
289.5 \mathrm{~K}-354 \mathrm{~K} .\end{array}$ \\
\hline
\end{tabular}

When the battery temperature is too high, it will make the membrane water loss to affect the proton conductivity of the membrane, so that the performance of the battery decreases. In air-cooled electric reactor, at the time of high temperature reducing proton conduction rate, the battery internal resistance increases and the battery temperature continues to rise so that leading to a sharp decline in the performance of the battery. However, the cooling temperature is higher, the temperature of the battery reduces more and wind speed changes in the cooling groove is more active. Thus the air flow can take away more heat and reduce the battery temperature.

\section{Conclusion}

This thesis analyzes the characteristics of the air forced convection cooling mode to the battery temperature. The influence of the variable convection cooling on the operating temperature is obtained by means of numerical simulation. Wind speed and temperature on the battery temperature have obvious effect. Different wind speeds of the battery temperature have different results. The air temperature increase leads to the rapid changes in wind speed and the heat that is taken away gradually increasing. The decreasing temperature of the battery increases. To control factors reasonably to make the battery in the best operating temperature range and reach the purpose of efficient operation.

\section{References}

[1] PHICHTA E J, HENDRICKSON M, THOMPSON R, et al.Develop-ment of low temperature Li-ion electrolytes for NASA and DOD application[J].J Power Sources, 2001, 94:160-166

[2] SMART M C, RATNAKUMAR B V, SURAMPUDI S. Electrolytes for low temperature lithium batteries based on ternary mixtures of aliphatic carbonates[J].J Electrochem Soc, 1999, 146:486-494

[3] NOBILI F, DSOKE S, MECOZZI T, et al.Graphite-metal oxide composites as anode for li-ion batteries[J].J Electrochim Acta, 2005,51:536.

[4] BERNADI D, PAWLIKOWSKI E, NEWMAN J. A general energy balance for battery systems[J]. J Electrochem Soc, 1985, 132 (1 ):5-12

[5] YANG H, AMIRUDDIN S, BANG H J,et al. A review of Li-ion cell chemistries and their potential use in hybrid electric vehicles [J].Journal of Industrial and Engineering Chemistry,2006, 12(1): $12-38$ 